\title{
Designing Co-Creation in the Circular City
}

\author{
Li-Ting Huang, Beatrice Villari \\ Politecnico di Milano \\ *Corresponding author e-mail: liting.huang@polimi.it
}

\begin{abstract}
:
Circular Economy (CE) is embedded in cities to promote inclusive, resilient, and sustainable lifestyles by design. Nevertheless, the transition from a linear to a circular lifestyle requires the collaboration of various stakeholders. Co-creation contributes and promotes unconventional methods as well as helps integrate resources from the city's key stakeholders. However, despite its prevalence in the private sector, the concept of co-creation has not been widely adopted in circular cities. As a continuation of previous studies, this paper aims at verifying the Circular City Cocreation Framework, chiefly constructed on the case studies of four prestigious circular cities. It delineates nine co-creation initiatives with actors involved and tools adopted to aid cities in transferring from linear to circular cities. To validate this framework, two circular cities - Gothenburg and Ljubljana - are examined extensively through case study analysis and semi-structured interviews. The results of this study revealed four main advantages of applying this framework.
\end{abstract}

Keywords: circular economy; circular city; co-creation design; co-creation framework

\section{Introduction}

Building momentum towards the climate-neutral city is essential, and the municipal authority needs to translate ambitious targets into specific policies and optional actions. In light of this, many municipalities undertake clear goals and strategies for the circular adjustment. These include working in a common direction, engaging local stakeholders, and promoting the market for circular products and services. For example, the Netherlands' national goal is to be fully circular by 2050 and cut down half of the raw materials by 2030. Local community-owned CE initiatives in Amsterdam adhere to the national strategy. There is a benefit in breaking down, interpreting, and adapting the strategies based on a clear CE focus of local circumstances. To a certain extent, the design offers a way of envisioning the future and creating change, and co-creation can be seen as a substantial factor in achieving CE goals (i.e., value preservation, resource optimisation, system effectiveness) (World Economic Forum, 2018). Numerous research projects centre the contribution of design towards the implementation of CE strategies. Frameworks, tools, and strategies are being developed from the design field to scale up these CE initiatives (Fleischmann, 2020; McAloone \& Pigosso, 2017; 
Wastling et al., 2018), ranging from the local to the national level. However, a shared framework is often overlooked. A framework with a common language for city stakeholders to reflect on and further guide co-creation activities is crucial for realising a circular city. Above all, the design community can contribute to advancing such processes more than merely facilitating, envisioning, and supporting.

This research extends the previous work and aims at verifying the Circular City Co-creation Framework, which is mainly constructed in four prestigious circular cities: Amsterdam, Brussels, Glasgow, and Helsinki, proposing nine co-creation initiatives with actors involved and tools adopted to help cities make the transition from linear to circular. In order to validate this framework, two circular cities - Gothenburg and Ljubljana - are examined in-depth through case study analysis and semi-structured interviews. By particularly underpinning the co-creation manner, nine co-creation forms are examined and discussed. The findings indicate that the Circular City Co-creation Framework can bring in at least four main benefits for city stakeholders, primarily for the municipality. To conclude, the authors draw attention to the co-creation practices in circular cities from planning to implementation and contribute to the field by providing a co-creation design approach to achieve a climate-neutral city.

\section{Framing co-creation activities in the circular city}

\subsection{Designing co-creation beyond the micro-level}

When applied to diverse contexts, the concept of co-creation can underline the systematic principle for businesses and customers (Prahalad \& Ramaswamy, 2004; Grönroos, 2012). For instance, cocreation can be related to the partnerships between public service and citizens (Voorberg, Bekkers, \& Tummers, 2015) or the shared responsibility (Lelieveldt et al., 2019). Frow, Payne, and Storbacka (2011) put forward that the advantage of subdividing co-creation into precise forms is that of centring innovative co-creation opportunities. With this aim, they expounded 12 forms to improve firms' capabilities on co-creation, describing various methods to adopt the concept when supporting firms (Frow, Payne, \& Storbacka, 2011). Additionally, in their later research, an updated framework was proven to be helpful for firms to identify new co-creation possibilities - such a strategic approach helps in developing innovation. Focusing on services, Oertzen et al. (2018) developed a detailed process to describe the specific forms of co-creating services, containing five 'co-' phases related to the different stages of the development process, from research to implementation. Moreover, from the viewpoints of Ramaswamy and Ozcan (2018), "co-creation is the enactment of interactional creation across interactive system environments (afforded by interactive platforms), entailing agency engagements and structuring organisations" (p. 5). The "interactional co-creation framework' developed by Ramaswamy and Ozcan (2018) stimulates thinking, where the potential value of participation will be generated in value co-creation from the perspective of the ends of experienced actors to empower actor networks. Above all, the growing dynamics of co-creation accompanied in an increasingly interactive way can be observed.

Co-creation is an approach to gather different groups of people, and it is the most relevant of all the human-centred approaches (e.g., systemic design, service design, participatory design, etc.). This leads us to its definition in design research, where Sanders and Stappers (2008) define co-creation as "any act of collective creativity, i.e., creativity that is shared by two or more people" (p. 6). Humancentred approaches are critical in implementing such cultural shifts across various government and stakeholder levels. The design's nature provides a positive direction in terms of the future and 
proactively contributes to what will come about next (Fuad-Luke, 2012). From the design's contribution, it is important that the best practices, processes, and tools can be developed and spread in various contexts. In this scenario, services and systems must be transformed to meet the main current challenges - such as climate change - and practical methods are required to co-create with different stakeholders.

\subsection{Towards a circular city co-creation framework}

A few CE-related frameworks have been launched in previous research to tackle the emerging challenges regarding the practical implementation of the circular city. Examples include the ReSOLVE framework (EMF, 2015), which turns three fundamental CE principles into six practical actions to generate circular strategies and initiatives. Another example is the Circular City Framework (CCF), which is based on the ReSOLVE framework delivered by Prendeville, Cherim, and Bocken (2018) combined with bottom-up and top-down interventions (Krauz, 2016; Ghisellini et al., 2016; Lieder \& Rashid, 2016). This framework outlines how the CE could be put into practice in an urban environment. However, there is an unbalanced way to involve stakeholders identified by them, because authorities rely excessively on leading businesses to guide civic society. The collaborative manner and partnership should be equally distributed within the different groups. As such, a feasible and thorough examination that can be adapted to different geographical scales is overlooked.

The Circular City Co-creation Framework provides city stakeholders (mainly the municipality) with a concrete method for performing co-creation initiatives constructed on tangible examples from the front runner circular cites mentioned before. Grounded on the ReSOLVE framework (EMF, 2015) and co-creation design framework defined by Frow, Payne, and Storbacka (2015), the Circular City Cocreation Framework contributes to generating potential CE activities, developing co-creation design methods to inspire further innovation and boost CE scenarios in cities. The six CE actions: ReSOLVE (i.e., regenerate, share, optimise, loop, virtualise, and exchange) labelled by the EMF is regarded as the principle of carrying out a circular city in the co-creation design framework. Seven categories of potential actors (i.e., the municipality, businesses, knowledge institutes, NGOs, citizens, local experts, and designers) that may engage in co-creation practices have been identified. Additionally, three main engagement platforms are included in the framework - considered as engaging platforms with the purpose of providing virtual resources, physical resources, and green events/festivals for communication, participation, experimentation, and further innovation. Most importantly, nine cocreation practices have been identified and classified into two major groups: (a) regenerative cocreation practices (i.e., co-vision, co-conception of ideas, co-design, co-prototyping, co-production, and co-promotion) intensify the strategic part of innovation to facilitate the implementation of the ReSOLVE framework (EMF, 2015); and (b) operative co-creation practices (i.e. co-maintenance, coconsumption, and co-sense) provide implementation strategies, balancing top-down municipal power, and bottom-up efforts from civic society. We draw attention to the co-creation practices in circular cities from planning to implementation and contribute to the field by providing a co-creation design approach to achieve a climate-neutral city. 


\section{Co-creation Activities}

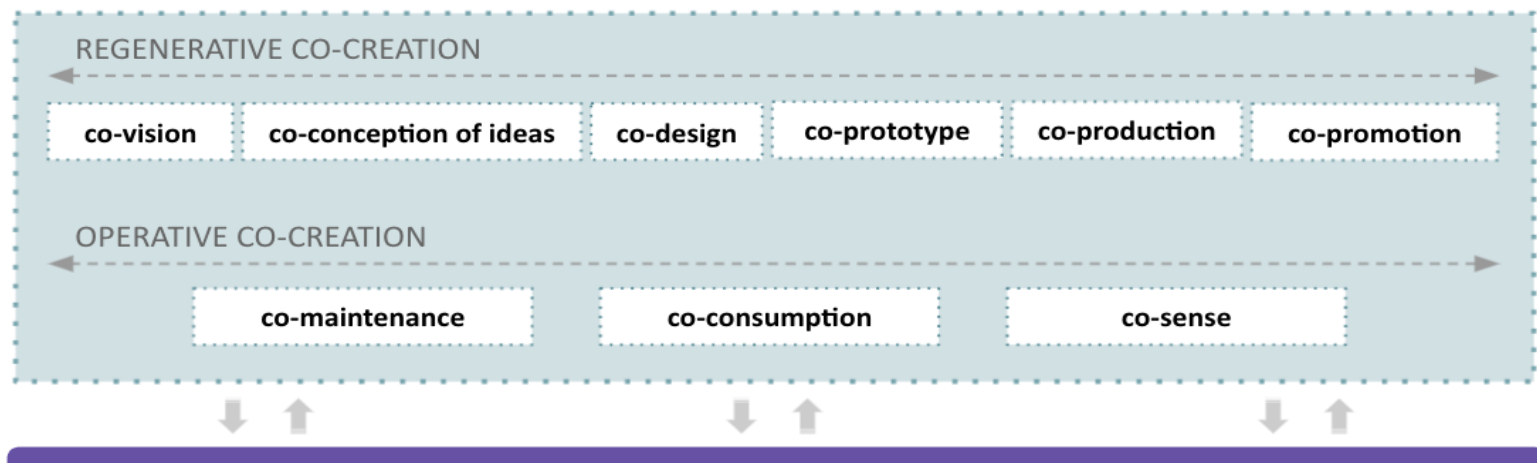

Stakeholders

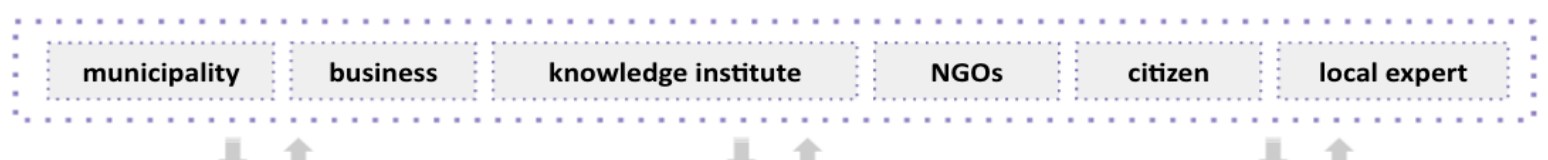

Enabling Platforms

digital resource

physical resource

event/festival

Fig. 1 Circular city co-creation design framework, adapted from the ReSOLVE framework (EMF, 2015).

\section{Methodology}

To verify the Circular City Co-creation Framework, two circular cities - Gothenburg and Ljubljana are examined extensively through a case study analysis and semi-structured interviews.

\subsection{Case study research}

A case study (Yin, 2009) was carried out to explore the co-creation phenomenon in a circular city. Focusing on different co-creation initiatives, case studies allow for identifying the implementation of the recommended CE co-creation practices in urban systems and taking into account a selection of actors and tools. The Circular City Co-creation Framework provides a design approach to apply cocreation activities in circular cities. It aimed to specify co-creation practices in circular cities and the potential contribution of the design in co-creation processes. The cities of Gothenburg and Ljubljana were chosen as (a) they both define themselves explicitly as circular cities; (b) they both implement a systematised circular city strategy (circular programmes/agendas at city/regional level instead of a single project); (c) engagement, involvement, or participation are emphasised in their co-creation process with citizens; and (d) availability of the information of two municipalities. As 'newcomers' to circular cities, these two municipalities stress the collaborative manner of working with stakeholders to achieve the desired results. These contexts are then examined through co-creation lenses to better understand how and in which part of the process the collaborative approach has been adopted. Documents from the municipalities - such as sustainability agendas and environmental programs - were reviewed to understand the city's CE goals, strategies, and co-creation forms. Further, practical cases from the official communication channels (i.e., digital platforms) were 
collected and studied to have a more comprehensive view of how co-creation is being developed in circular cities.

\subsection{Semi-structured interview}

Based on the Circular City Co-creation Framework proposed by authors, semi-structured interviews were undertaken with the circular city project managers of Ljubljana as well as the planning leader of Circular Gothenburg and a service designer to validate the relevance, comprehensiveness, and transferability of the framework. Semi-structured interviews enable interviewees - listed in Table 1 to grant insight into how these co-creation activities are executed and the stakeholders and platforms are involved. Through interviews, nine co-creation categories were discussed and supported with concrete examples. The interview process was divided into three parts. In the first part, we briefly explained the concept of co-creation. The second section of the interview focused on the co-creation activities that occur inside the circular city. Each co-creation form was explained, then, we asked interviewees if they have ever devoted time to such co-creation activities in their cities. Detailed explanations are provided by interviewees, including stakeholders involved and engaging platforms applied. The last section concerns the reflection and feedback of the framework.

Overall, this framework was appreciated by city managers for its relevance and usability for providing such design tools. Both interviewees said that they believed using various co-creation methods is essential in addition to expressing the need for such activities in practical terms. Simultaneously, the feedback specifies that the framework should be adjusted based on local situations. In other words, it should be feasible enough to meet the local context. On the other hand, the interview with the service designer focuses on the actual application of this framework regarding opportunities and limits from a practical perspective. In particular, on the value of co-created knowledge and the "know-how" to utilise the service design tools for achieving a future-proof city.

\begin{tabular}{|l|l|l|}
\hline Organisation & Title & Type \\
\hline City of Ljubljana & $\begin{array}{l}\text { Ljubljana Circular Economy } \\
\text { Manager }\end{array}$ & 60 -minute online interview \\
\hline City of Gothenburg & $\begin{array}{l}\text { Planning Leader Circular } \\
\text { Gothenburg }\end{array}$ & 40-minute online interview \\
\hline Snook & Service Designer & 40-minute online interview \\
\hline
\end{tabular}

Table 1. Experts interview for validating the framework

\section{Results: validating nine co-creation categories}

The following section presents the results of the nine co-creation activities in two 'growing' circular cities - Ljubljana and Gothenburg, which are chiefly constructed on the case studies of four prestigious circular cities: Amsterdam, Brussels, Glasgow, and Helsinki. Overall, two of the activities in the cities co-prototyping and co-sense - are not as prosperous as in those cities. Moreover, the diversity of different co-creation categories can be detected from the case study and interview process. In Gothenburg, stakeholders who participate in the co-creation activities relating to CE are mainly constituted by the authority, experts, researchers, and companies. With less than half the population of Gothenburg - Ljubljana is one of the smallest capitals in Europe - the co-creation forms are 
tendentially performed in a collective way extending to citizens. The public sector takes up the leading role, together with several businesses, institutions, and civic society, to disseminate CE practices. While we tend to discover city-wide co-creation (relating to $\mathrm{CE}$ ) projects and activities, the scale of the initiatives remains relatively small in Ljubljana. Below each co-creation activity is discussed in detail:

(1) Co-vision

Depending on regional conditions, co-vision refers to mapping out the desired future shared by the municipality, civic society, and related stakeholders. Commonly, the city-level CE roadmap follows its national guideline. For instance, the leading role in the CE transition which belongs to the Netherlands - aims at being fully circular by 2050 and cutting down half of its raw materials by 2030. By effective communication, co-vision unites the city's various actors with clear incentives, since it is significant to triggering faith and enhancing hope with a shared view.

- Ljubljana: The vision of Ljubljana is closely tied to the SDGs and covers crucial national instructions (e.g., A Vision for Slovenia in 2050). Within Slovenia, the involvement of multiple stakeholders facilitating the transition from a linear city to a $\mathrm{CE}$ is based on the so-called 'Circular Triangle' framework, combining three groups - the businesses, government, and citizens.

- Gothenburg: The city of Gothenburg has embraced Sweden's national strategy, which stresses on CE-related production, consumption, and business models. The construction sector is the focus area that is underlined within the local government. The Gothenburg municipality stated that the CE transition must be carried out jointly by politics, businesses, the public sector, academia, and civil society.

(2) Co-conception of ideas

Co-conception of ideas refers to actors collaborating on concept innovation. Circular Glasgow is one of the outstanding large-scale crowdsourcing examples. Propelled by the Glasgow Chamber of Commerce, Circular Glasgow seeks to engage local businesses in producing major city events and conferences. It also promotes $\mathrm{CE}$ ideas related to global challenges by inviting individuals and businesses that contribute to generating circular ideas within the events sector online.

- Ljubljana: The municipality has issued public calls for ideas and descriptions of sustainable products. Projects selected by the expert committee will be combined into an internal e-catalogue of sustainable products, with the municipality aiding in their promotion.

- Gothenburg: In centralising the co-conceptions of ideas and activities in the city of Gothenburg, one of the special events issued by the local government (Open Innovation Day) is a call for an innovation competition to minimise the climate impact of its citizens. Several innovative solutions emerged to guide citizens into developing awareness of climate change.

(3) Co-design

Co-design refers to actors/designers sharing their design perspectives, respectively, especially in the 'fuzzy front-end' phrase. Citizens explore possibilities and gain inspiration by codesigning practices related specifically to collaborative workshops. Remarkably, the city of Helsinki appeared very active in developing co-design activities, with a focus on intelligent transportation. Taking the district of Jätkäsaari in Helsinki as an example, designers engaged residents in solving local mobility challenges. 
- Ljubljana: APPLAUSE in Ljubljana - one of the Urban Innovative Actions (UIA) projects - addresses the unsolved questions about invasive plant species associated with the zero-waste approach and CE. Within the project's framework, the City of Ljubljana collaborated with designers and its citizens to develop several products together.

- Gothenburg: A shared physical or virtual development environment in Gothenburg Virtual Gothenburg Lab - functions as a platform for many to co-design together. As a testbed for society's challenges, companies, non-profit actors, academia, institutes, and other organisations collaborate here to develop, test, and implement products and services

(4) Co-prototyping

Co-prototyping refers to two or more actors collaborating on proposing innovative solutions and implementing them in a flexible and co-creative way with mock-ups or service rehearsals. For example, a model in the Smart Kalasatama district of Helsinki - the Agile Piloting Programme - has been developed to experiment with new services and technologies in the real-world environment.

- Ljubljana: The Ljubljana and Drago programme transformed a decommissioned city bus into a Mobile Youth Centre since some public space was insufficient to completely realise this project. The youngsters participating in the programme are led and guided by experienced experts from creative industries and experiment with new services and technologies in a co-creative way.

- Gothenburg: The co-prototyping activity has not advanced properly to civic society, i.e., it is limited to specific groups of people. Serving as a national and collaborative arena, the digital twin platform enables the exchange and accessibility of interaction and experimentation of the city. Led by experts, activities on the platform are motivated by improving citizens' well-being and the circularity of materials inside cities.

(5) Co-production

Co-production emphasises an equal and reciprocal partnership (NESTA, 2009) among users while delivering public services. Co-production activities can be arranged in both digital or physical spaces (e.g., Urban Living Labs, Fab Labs, maker spaces, incubators, innovation hubs, etc.), and distributed urban production systems are necessary to explore the potential for a new dynamic of the city enabled by new technologies.

- Ljubljana: The RogLab Center was designed as a production, educational, and presentation space that acts as a mini-hub of creative activities with an emphasis on the accessibility of production tools. Its purpose is to develop products or services on a small scale and test them in a practical context. In the centre, creative projects are produced responding to the challenges of modern society and urban environment, with a network of partner institutions and cross-sectoral networking.

- Gothenburg: The city contains a living lab for research on the sustainable living environment which contains almost thirty apartments where researchers and students live while innovation and research are carried out in their living environment. The HSB Living Lab aims on creating innovations on-site that can help enhance the quality of future homes and buildings, providing a ground for an improved understanding of sustainability and collaboration between the industry, city, and academia. 
(6) Co-promotion

Co-promotion is described as multiple actors collaborating on promotional activities related to a specific product, brand, or entity. Here, co-promotion indicates advocating a green lifestyle.

- Ljubljana: After winning the title of European Green Capital in 2016, Ljubljana has significantly strengthened its 'green' recognition worldwide, upgrading the city's brand and putting it on the map of leading sustainable tourist and innovative cities. Many projects and measures contrive in Ljubljana have a common goal - to ensure a high quality of life for every generation in a safe and green city.

- Gothenburg: GreenhackGBG is the primary channel for promoting sustainable lifestyles, where co-creation is in focus. This platform helps Gothenburg's citizens and businesses implement sustainable practices collectively, allowing ideas, thoughts, and knowledge to be exchanged. Thus, the municipality created a platform for social, economic, and ecological sustainability by both talking about and pushing for the transition to a more sustainable Gothenburg.

(7) Co-maintenance

Co-maintenance is related to actors sharing either the maintenance service or a core product or service. Partly stemming from the concept of the repair café, co-maintenance activities entail the involvement of volunteers in different professions (e.g., electricians, tailors, carpenters, etc.). Co-maintenance culture is widespread in Amsterdam, Brussel, Glasgow, and Helsinki.

- Ljubljana: The project - Don't buy, fix! - seeks to make young people aware of excessive consumption and its negative impacts on the environment. The campaign focuses on promoting repairing and recycling materials, such as furniture, electronics, clothing, and bicycles. Moreover, the Ljubljana municipality itself sets an example in many areas.

- Gothenburg: At the Gothenburg co-maintenance exchange corner - Fixoteket, citizens can hand in items (e.g., household utensils, home electronics, small furniture, and ornaments, etc.) or borrow tools. Additionally, in Alelyckan Re-use Park, residents can bring products to be recycled, donate reusable materials, or buy goods donated by others. Further, the Bike Kitchen, an open DIY repair workshop, allows anyone to come in to fix or build a bike from the recycled spares. Such places demonstrate the dynamic co-maintenance manner in Gothenburg.

(8) Co-consumption

Co-consumption entails collaboration during usage, as actors employ their resources (physical, social, or cultural) individually or collectively when consumers determine and enhance their own consumption experiences.

- Ljubljana: Sharing bicycles can be rented, with the first hour being free through registration with a city card. Another example, the electric car charging model Avant2Go, only uses vehicles that are $100 \%$ electric.

- Gothenburg: Residents in the area around Gothenburg, are beneficiaries of the city's Smart Map, a digital map that relies on the participation of local inhabitants and a public partnership, promoting a sustainable lifestyle by encouraging citizens to find alternatives for sustainable consumption. On the map, users can find bicycle kitchens, 
exchange groups, free shops, carpools, and various digital platforms where local stakeholders help shape co-consumption activities and utilise resources efficiently.

(9) Co-sense

Co-sense refers to actors collaborating on using daily and readily accessible technology to detect and collect data. With accessible toolkits and ground-breaking new technologies, cosense activities depend heavily on contextual resources. These types of activities are widespread in the cities of Amsterdam, Helsinki, and Glasgow. A remarkable instance of such - developed from the Dutch Cinekid Festival of 2016 - is the Smart Kids Lab, where children observe the environment (e.g., soil, liquid, and air) by using small-scale tests and self-made sensors.

- Ljubljana: Although co-sense activities are not as prevalent as in the aforementioned CE cities, some scattered co-sense-related events can be found in RogLab. One of the examples associated is the workshop for children - ROGoFlore robots, which are made with waste bags and assembled electronic elements, robots can detect humidity.

- Gothenburg: Co-sense activities are restricted to research projects in Gothenburg. One interesting case is the Viable Cities Transition Lab. This project aims to co-create a common ability to meet significant societal challenges such as climate and environmental transitions. Two significant climate challenges are addressed: transport and energy efficiency in buildings. Intelligent sensors for measuring air quality are increasingly employed in control systems.

\section{Discussion}

The proposed Circular City Co-creation Framework represents the early phase of organising, visualising, and describing how co-creation activities can be adopted in supporting circular cities' transformations. Apart from the detailed descriptions of each co-creation form appearing in their cities, some key aspects were highlighted in the interview process. The four advantages of the Circular City Co-creation Framework include the following:

(1) Embedding social concern within circular economy framings

Adopting this framework helps in redeeming the lack of social concern of the $\mathrm{CE}$, which has been overlooked in national or regional CE guidelines. As the interviewee described: "(...) the social issues should be included in our strategy because, in our national [CE] strategy in Sweden, these things [social issues] were not very much included or not enough included (...) in the CE model, and cocreation can make up for the deficiency" (Circular Planning Leader, Gothenburg).

(2) Providing actionable solutions for the realisation

The framework transfers the acquired knowledge and practices in specific sectors into actionable approaches: "(...) even if we are trying to talk to the citizens, I think it would be good to have a flexible method that can be adapted in different situations (...) because you cannot use it exactly the same way in different areas, but I think it would be good to have more knowledge to know how to do it" (Circular Economy Manager, Ljubljana).

(3) Functioning as a guideline and a common language

Using a variety of co-creation engagement methods was considered significant by the interviewee: "I think the method [the circular city co-creation design framework] will (...) remind us that we can cocreate in very many different stages, so we don't just do it at the beginning, it's like a process with 
different steps, also in many different areas (...), as a common way of working. So, I think that's quite new for us (...)" (Circular Planning Leader, Gothenburg).

(4) Facilitating innovation among stakeholders

The interviewee remarks that from their experience, adopting co-creation activities also accelerates innovation especially with technological partners, "... we have regarded our technological partners as very important stakeholders (...), we support different start-up initiatives by mentoring and cooperating and they've been very successful (...)" (Circular Economy Manager, Ljubljana).

The proposed circular city co-creation framework can support the municipality in crafting a comprehensive circular strategy, which informs collaboration. Furthermore, it helps municipalities promote co-creation culture and encourage transparent conversations. Although limited in terms of the number of interviewees, the findings of our study support previous ones and broaden the scope of the ongoing discussion for future research. Overall, four points are set out for the improvement of this framework: (1) making explicit descriptions of each co-creation activity with examples to help the shareholders better understand the content of each; (2) providing specific (design) tools for setting up co-creation sessions that are feasible and adaptable to local conditions, for instance, City Portrait Canvas (DEAL et al., 2020) and Circular Design Guideline (IDEO \& EMF, 2017); (3) clustering co-creation activities with procedures to guide stakeholders when applying the framework to different topics (e.g., food, waste, energy, mobility, construction, etc.); and (4) providing an analytical approach that allows the city's stakeholders to better assess the co-creation activities they adopt. In view of the above, more extensive research will be explored in the future.

\section{Conclusions}

Design provides a way to imagine the future, develop, and test solutions, and the potential of human beings to co-create jointly is essential to solving global climate challenges. This research extends the probability of design within the $\mathrm{CE}$ and explores different co-creation forms that can be applied to achieve a climate-neutral and circular city. The transferability of the proposed Circular City Cocreation Framework is examined and further validated by case studies and semi-structured interviews. Case studies allow the identification of the implementation of recommended CE cocreation practices in urban systems taking into consideration a selection of actors and tools. However, a few research limits were identified. In general, the effectiveness of this framework is hard to assess, as the degree of urban sustainability is difficult to evaluate. Besides, the cases discussed in this paper focus on the European context, and considering many aspects, they are relatively prosperous compared to other countries. Therefore, there might exist barriers when applying the same to other cities.

This research suggests four dimensions that the Circular City Co-creation Framework brings about. It is essential in promoting new models and integrating alternative sources where people can actively participate in the path towards a sustainable urban future. Further extensive research will be executed in this regard in the future. This includes making clear descriptions of each co-creation activity, providing specific tools for the co-creation section that are feasible and adapt to local conditions along with the support of other (design) tools, clustering co-creation activities with several steps when applying to different subjects, and providing an analytical approach to better assess co-creation activities. Further research will be able to determine the solutions to such issues from a whole systemic dimension and address operational functions from a design perspective. 


\section{References}

Doughnut Economics Action Lab. (2020). The Amsterdam city doughnut: A tool for transformative action. https://www.circle-economy.com/resources/the-amsterdam-city-doughnut-a-tool-fortransformative-action

Ellen MacArthur Foundation. (2015). Delivering the circular economy: A toolkit for policymakers. https://www.ellenmacarthurfoundation.org/publications/delivering-the-circular-economy-atoolkitfor-policymakers

Ellen MacArthur Foundation. (2017). Cities in the circular economy: An initial exploration. https://www.ellenmacarthurfoundation.org/publications/cities-in-the-circular-economy-aninitialexploration

Ellen MacArthur Foundation \& IDEO. (2017). The Circular Design Guide. https://www.circulardesignguide.com/

European Commission. (2019). Communication from the commission to the European parliament, the European council, the council, the European economic and social committee and the committee of the regions: The European Green Deal. https://eur-lex.europa.eu/legalcontent/EN/TXT/?qid=1576150542719\&uri=COM\%3A2019\%3A640\%3AFIN

Fleischmann, K. (2020). Designers as change agents in the circular economy. Discern: International Journal of Design for Social Change, Sustainable Innovation and Entrepreneurship, 1(1), 99-118.

Frow, P., Nenonen, S., Payne, A., \& Storbacka, K. (2015). Managing co-creation design: A strategic approach to innovation. British Journal of Management, 26(3), 463-483. https://doi.org/10.1111/1467-8551.12087

Frow, P., Payne, A., \& Storbacka, K. (2011, November). Co-creation: A typology and conceptual framework. In Proceedings of ANZMAC (pp. 1-6).

Fuad-Luke, A. (2012). Co-designing services in the co-future city. In Kuosa, T., \& Westerlund, L. (Eds.), Service design: On the evolution of design expertise (pp. 101-120). https://core.ac.uk/download/pdf/38075582.pdf

Ghisellini, P., Cialani, C., \& Ulgiati, S. (2016). A review on circular economy: The expected transition to a balanced interplay of environmental and economic systems. Journal of Cleaner Production, 114, 11-32.

Girard, L., \& Nocca, F. (2019). Moving towards the circular economy/city model: Which tools for operationalising this model?. Sustainability, 11(22), 6253.

Grönroos, C. (2012). Conceptualising value co-creation: A journey to the 1970 s and back to the future. Journal of Marketing Management, 28(13-14), 1520-1534.

Krauz, A. (2016). Transition management in Montreuil: Towards perspectives of hybridisation between 'top-down' and 'bottom-up' transitions. In Governance of urban sustainability transitions (pp. 133-150). Springer. http://ido.org/10.1007/978-4-431-55426-4_8

Lelieveldt, H., Dekker, K., Völker, B., \& Torenvlied, R. (2009). Civic organizations as political actors: Mapping and predicting the involvement of civic organizations in neighborhood problem-solving and coproduction. Urban Affairs Review, 45(1), 3-24. https://doi.org/10.1177/1078087409332303

Lieder, M., \& Rashid, A. (2016). Towards circular economy implementation: a comprehensive review in context of manufacturing industry. Journal of cleaner production, 115, 36-51. https://doi.org/10.1016/j.jclepro.2015.12.042

McAloone, T. C., \& Pigosso, D. C. (2017). From eco-design to sustainable product/service-systems: A journey through research contributions over recent decades. In Sustainable Manufacturing (pp. 99-111). Springer.

NESTA. (2009). The challenges of co-production. How equal partnerships between professionals and the public are crucial to improving public service. https://neweconomics.org/uploads/files/312ac8ce93a00d5973_3im6i6t0e.pdf 
Organisation for Economic Co-operation and Development. (2020). The circular economy in cities and regions: synthesis report. https://www.oecd-ilibrary.org/sites/10ac6ae4en/index.html?itemld=/content/publication/10ac6ae4-en

Oertzen, A.-S., Odekerken-Schröder, G., Brax, S.A. and Mager, B. (2018). Co-creating servicesconceptual clarification, forms and outcomes. Journal of Service Management, 29(4), 641-679. https://doi.org/10.1108/JOSM-03-2017-0067

Prahalad, C. K., \& Ramaswamy, V. (2004). Co-creation experiences: The next practice in value creation. Journal of Interactive Marketing, 18(3), 5-14. https://doi.org/10.1002/dir.20015

Prendeville, S., Cherim, E., \& Bocken, N. (2018). Circular cities: Mapping six cities in transition. Environmental innovation and societal transitions, 26, 171-194. https://doi.org/10.1016/j.eist.2017.03.002

Ramaswamy, V., \& Ozcan, K. (2018). What is co-creation? An interactional creation framework and its implications for value creation. Journal of Business Research, 84, 196-205. https://doi.org/10.1016/j.jbusres.2017.11.027

Sanders, E. B. N., \& Stappers, P. J. (2008). Co-creation and the new landscapes of design. Co-design, 4(1), 5-18. https://doi.org/10.1080/15710880701875068

Selloni, D. (2017). CoDesign for public-interest services. Springer. https://doi.org/10.1007/978-3-31953243-1

United Nations. (2015). Transforming our world: the 2030 agenda for sustainable development. https://www.un.org/ga/search/view_doc.asp?symbol=A/RES/70/1\&Lang=E

Voorberg, W. H., Bekkers, V. J., \& Tummers, L. G. (2015). A systematic review of co-creation and coproduction: Embarking on the social innovation journey. Public Management Review, 17(9), 13331357. https://doi.org/10.1080/14719037.2014.930505

Wastling, T., Charnley, F., \& Moreno, M. (2018). Design for circular behaviour: Considering users in a Circular Economy. Sustainability, 10(6), 1743. https://doi.org/10.3390/su10061743

World Economic Forum. (2018). Circular economy in cities: Evolving the model for a sustainable urban future.

http://www3.weforum.org/docs/White_paper_Circular_Economy_in_Cities_report_2018.pdf

\section{Author Bios:}

Li-Ting Huang PhD candidate in the Design department, Politecnico di Milano. Her current expertise lies in the field of service design and believes that design practitioners can play in moving towards a more sustainable future.

Beatrice Villari PhD in Design. Associate Professor at the Design Department, Politecnico di Milano and co-director of the Specializing Master in Service Design. Her main research interests are focused on service innovation, service design, design for social innovation, and design for policy and governments. 